\title{
A Review on Gas Supply System of Liquefied Natural Gas Vehicle
}

\author{
Ping Fang and Yu Chen
}

\begin{abstract}
This paper describes the current development status of Liquefied Natural Gas (LNG) automotive gas supply system. The technical defects of the gas supply system, such as low vaporization, cold start, low storage time of LNG and high ignition energy, are showed. Finally, a summary of the research on liquefied natural gas supply system is made, which puts forward the technical routes optimizing the carburetor and increasing the storage time of LNG in the gas cylinder. As a result the future development of LNG supply system is prospected.
\end{abstract}

Index Terms-LNG (liquefied natural gas), gas supply system, manufacturability.

\section{INTRODUCTION}

With the continuous development of social economy and the rapid increase of car ownership, the total energy demand of traffic transportation industry in China shows strong growth momentum. At the same time, the problems including the contradiction between supply and demand of oil, greenhouse gas emissions and urban air pollution problems have worsen. Therefore the promotion and development of natural gas vehicle as the representative of new energy vehicles is imperative.

In recent years, LNG vehicles have been widely used in large buses and heavy trucks. Gas supply system is the core part of power structure of LNG vehicle, including motor LNG cylinders, automotive carburetor, fuel gas supply unit, as well as the safety device and so on [1].

The natural gas vehicle, with its significant environmental advantages, known as "green car", is still faced with many technical problems, especially technology of fuel gas supply loop stability has not been completely resolved. When vehicles climb or accelerate, it can appear the phenomenon of insufficient gas supply, which can causes serious engine surge or flameout. Therefore, it is the primary technical problem how the gas supply system can guarantee the dynamic demand of the car under arbitrary working conditions.

Manuscript received February 13, 2018; revised January 23, 2019. This work was supported in part by the U.S. Department of Commerce under Grant BS123456.

Ping Fang is with College of Mechanical Engineering, Shanghai University of Engineering Science, Shanghai, China (e-mail: 1833786941@qq.com).

$\mathrm{Yu}$ Chen is with the Department of Thermal Energy and Power Engineering, the Institute of Mechanical Engineering, Shanghai University of Engineering and Technology, Shanghai, China (e-mail: yvettee1976@126.com).

\section{RESEARCH StATUS OF GAS SUPPly SySTEM}

Developing the LNG vehicles is one of the important measures of the advanced countries to carry out the environmental protection and energy policy. In the expansion and technology application of LNG vehicle ways, the United States has been in a leading position and has more than half of the world's LNG filling station and LNG vehicles. MVE company of the United States is one of the main manufacturer of producing LNG equipments in the world, its products include LNG gas cylinder for automobile, LNG filling station, LNG automatic aerator and large LNG storage tanks, etc [2].

\section{A. LNG Gas Cylinders}

In 1906, Scottish physicist and chemist James duval invented a metal dewar bottle containing liquid oxygen. This bottle used to store LNG, so it's commonly known as a "LNG carbottle” [3]. LNG cylinders is mainly composed of the tank, shell, thermal insulation structure, the support system and accessories, etc. As is shown in Fig. 1 [4].

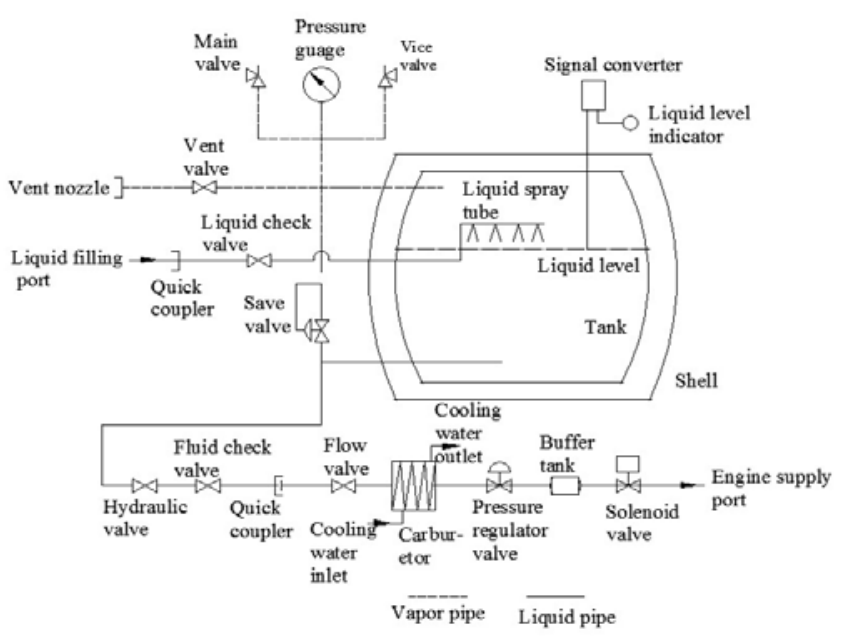

Fig. 1. LNG bottle body structure for vehicle.

The integral structure of LNG cylinders is equipped with liquid spray tube, liquid discharge pipe and gas discharge pipe and so on. The space between the tank and the shell is pumped into vacuum and forms the good vacuum insulation system. The outer wall of the tank coil is composed of smooth glass fiber paper and aluminum foil of multilayer insulation materials. Generally, the fixed way of one end fixed and one end free sliding is adopted between the inner liner and the outer shell, so that the safety factor in the use process of the tank is improved [5].

LNG cylinders are divided into two types: horizontal and vertical cylinders [6]. Generally, horizontal cylinders are used in vans. According to LNG liquid output, LNG 
cylinders can be divided into two types: conventional cylinders and pressurized cylinders [7]. LNG liquid in the conventional cylinders from the liquid outlet valve output tube into a water bath vaporizer is in a liquid pressure balance (usually around $0.5 \mathrm{MPa}$ ) and keep this pressure output LNG liquid. Pressurized cylinders are divided into two types: inter pressurized cylinders and outer pressurized cylinders. In the inter pressurized cylinders, a low-temperature booster pump can pressurize the output LNG. The outer pressurized cylinders add a set of evaporation loops to the LNG cylinder. In addition to the classic pressurized system, there are electric heating type, gas return type and vacuum type pressurization system [8]. The cylinders of these pressurization systems ensure the pressure in the cylinder effectively and meet the requirements of the engine.

The LNG cylinders manufactured by the NexGen Company under Chart Company use the patented technology based on gas-liquid thermal dynamic equilibrium. The support material of the cylinder is mainly stainless steel, with high vacuum and multilayer insulation. It has a good thermal insulation performance. In addition, the vibration and impact of the vehicle under normal driving conditions, the gas cylinder can work more safely and reliably [9].

Our country has a technical foundation in the adiabatic technology, vacuum technology, supporting structure and pipeline. The cooperation of Shanghai Jiao Tong University and Shanghai sunwin bus company and other units make a study of the key components of the liquefied natural gas in the gas supply system, and test the CumminsCG-250 engine, On this basis, they developed SWB6115LQ-3 type liquefied natural gas buses, and the vehicle dynamic performance and the emission index meet the requirements.

\section{B. Automobile Carburetor}

The carburetor is an important device which makes LNG from liquid to gas, installed between the vehicle and the engine cylinders. According to heat sources, the carburetor can be divided into the heated carburetor, environmental carburetor and process carburetor [10]. A car currently used for carburetor is water bath type shell and tube evaporator, as shown in Fig. 2 [11].

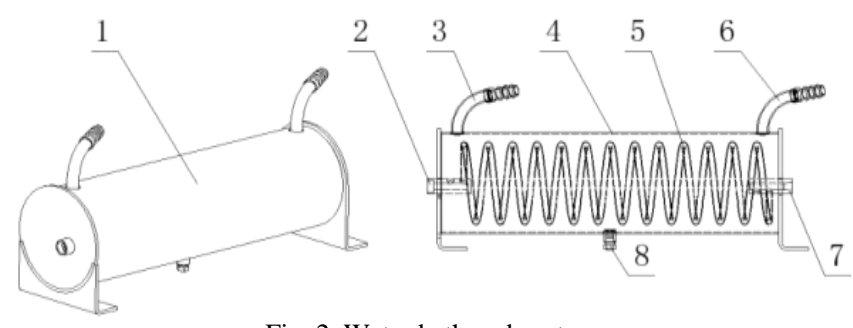

Fig. 2. Water bath carburetor.

Water bath carburetor has many advantages, such as simple and compact structure, high thermal efficiency and less environmental impact and it is widely used in vehicle LNG supply system. The working principle of a water bath vaporizer is that the liquid or gas-liquid mixed LNG flows into the carburetor inlet 2, and passes through the spiral tube 5 , then it flows out of the carburetor outlet 7 in a gaseous form after absorbing heat. The high temperature coolant from the engine flows through the space between the spiral tube and the shell, exchanging heat with the LNG in the tube to vaporize the LNG, then back into the cooling cycle and continue to participate in the cooling of the engine. The traditional carburetor has some deficiencies in the work process, such as cold start when the water temperature is too low, the gas temperature of gasifier outlet is too low, the heat of cooling water is not enough when the car uphilling or downhilling, and cooling water flow is effected by the scale. According to the defects of the traditional carburettor, both at home and abroad has made a series of research.

Wärtsilä Company in Finland used an intermediate heat transfer medium in the temperature control process. First they heat the transfer medium in the low temperature water, then the transfer medium can vapor the LNG. This way can meet the requirements of controlling LNG based on the temperature of transfer medium [12]. The engine the UK -Rolls-Royce Company also uses this method to control the temperature of the LNG, and the transfer medium is a mixture of water and glycol. They will heat the LNG after the heat exchange in the gasifier.

$\mathrm{Li} \mathrm{Na}$ of the Shandong University raised a system of combining LNG engine and heater of vehicle gas against the low gasification temperature. In this system, gas heater is added to the LNG fuel supply system, for LNG gasifier exports of natural gas to be heated [13]. Yuan Huiling of the Taiyuan University of Technology developed a constant temperature vaporizer, which heated the sheets evenly to the inside of the shell of the vaporizer and heated the coolant [10].

\section{Gas Supply Device}

The gas supply unit refers to the gas supply unit and control device of the rear end of the automobile gasifier, including the inlet valve, buffer tank, stabilizer valve, mixer and solenoid valve [4].

The inlet valve is used to control the filling of the low temperature LNG liquid, which is connected to the valve before the valve.

Buffer tank is installed in the end of the gas supply system, tank reserve a certain amount of gas, when you need a larger volume and evaporation is insufficient, it can provide additional capacity in order to avoid lack of supplies.

Stabilizer valve is installed between the carburetor and solenoid valve, normally the maximum working pressure of the gas in LNG cylinders is not allowable for the LNG engine, so we should regulate the pressure before supplying gas for the engine to meet the technical requirements.

Mixer is a mechanical device which uses the principle of venturi to ensure that air and fuel can be mixed in the correct proportion in both static and dynamic condition [14]. The main purpose of mixer is to mix the natural gas and air as much as possible in a certain proportion to form a certain concentration of combustible mixture. According to the variation conditions of the speed and load, adjusting the supply of combustible mixture to meet the requirements of different conditions such as low load, medium load and high load [15], [16].

The role of solenoid valve is to break the gas, control and adjust the gas. The engine of the vehicle is not activated but the total power supply is still in the state of connection and it 
can ensure the gas line is closed.

\section{Safety Device}

The safety device runs through the entire supply system, including the main secondary safety valve, the cylinder level gauge, the manual emptying valve, the overflow valve and the check valve.

There are two levels of safety valve in the LNG cylinder: the main and auxiliary safety valve. When the pressure is exceed, the safety device plays a protective role. First, open the main valve in the overpressure condition, when the main safety valve loses efficacy, auxiliary safety valve will work.

The main function of the liquid level gauge is to monitor the change of liquid level in the LNG cylinder. The liquid level gauge adopts the anti-vibration and anti-pollution, which can effectively prevent overcharging. The principle is shown in Fig. 3 [17].

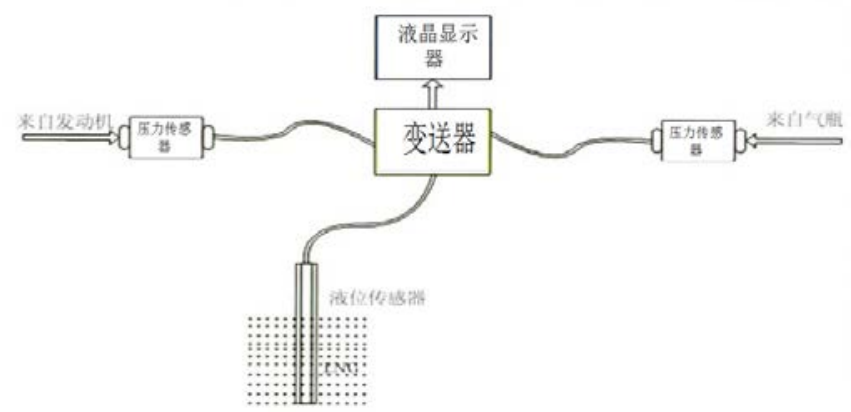

Fig. 3. Working principle of liquid level display system.

Transmitter can connect two pressure sensors and a liquid level sensor, one from LNG cylinders and another from the engine. The conversion and processing of all analog data via the transmitter and the final data is conveyed to the liquid crystal display. The display shows level surplus quantity, so that the driver can inform the fuel usage in time.

The overflow valve and check valve are all components of the safety device. The main function of the overflow valve is to avoid the gas leakage and other situations. When the gas flowing in the pipeline exceeds the threshold, the overflow valve is putting into the working state. Check valves can prevent the gas flowing backwards. The valve of the safety device needs good sealing and reliability in order to provide a good working environment for the whole gas supply system.

\section{PROCESS ANALysis OF GAS SUPPly System}

\section{A. Saturation Pressure Supply System}

According to the saturated dynamic principle of the gas and liquid pressure, the saturation pressure system can provide the gas which is consistent with the saturation pressure, generally can reach $0.2 \sim 0.5 \mathrm{MPa}$. It can meet the requirements of the gas engine which adopts the control system of using theory air-fuel ratio, without pressure, stepper motor controlling or electric diaphragm proportioner. However it can't meet the requirements of the high power gas engine which need greater flow of gas [18].

\section{B. Self-Pressurization Supply System}

The structure of the self-pressurization system is that close to the lower position of the inner head of the LNG gas cylinder valve and opening a pore with stainless steel pipe through the vacuum layer from the outer head to the lower end position, and it should ensure the sealing of the inner and outer parts of the tank. When the self-pressurization system is working, the pressurization valve will open and the liquid flows from the cylinder under the gas phase pressure and gravity of the liquid. In the process, the heat transfer with outside air has be completed. The pressure of liquid can be raised via vaporization and the liquid will get into the gas phase in the cylinder, which can increase the pressure in the cylinder to the demand pressure. The effect on the liquid pressure makes a liquid at the same pressure from the valve chest part of the liquid flow through the pressurization valve, over-current protection valve into the carburetor and then storaged in a buffer tank.

\section{Low Temperature Pressure Pump Supply System}

The structure of the low temperature stress pump system is that inserting into the pressure pump in a cylinder valve box end, make sure the tank and the shell head parts of a vacuum insulation. TCU should be set in the system to communicate with the engine. The principle of system is to realize the automation and intelligence of LNG supply. The low temperature pressure pump system shows obvious technical and market advantages, but the cost is too high.

\section{TeChnical Defects of the Gas Supply System}

LNG vehicle can be modified by fuel supply system on the base of traditional engines. The process is simple, and generally need to add air supply control system and gas supply system. Although the modification cost don't need too much, but the modified LNG vehicle compared with the original vehicle, there are some shortage of place.

1) The low volume of gas leads to a decrease in the power of the engine. The amount of air charge is reduced during the intake process of the natural gas, and the interference or resistance to flow may be caused in the mixer. Therefore, the charging efficiency may be reduced [19].

2) When the LNG vehicle in northern winter, the temperature of coolant liquid is the same as the environment. The flow of coolant liquid will reduce under low speed of engine and LNG gasification may not fully, which causes the engine gas supply shortage and difficult cold start. In addition, the released cooling capacity may also prolong process of warming up the engine [20].

3) Igniting natural gas mixture needs large ignition energy, and measures to increase ignition energy are usually made by using natural gas special high energy igniter or improved traditional igniter. Engine needs a mixture of greater concentration and concentration of heavy gas mixture should consider of the low charging efficiency of engine. Therefore, choose an engine with larger compression ratio or take the cylinder LNG liquid jet which improves the technology of LNG vehicle and cost [21], [22]. 


\section{CONCLUSION}

This paper analyzes the process and equipment of LNG vehicle gas supply system and summarizes the development status of gas supply system of LNG at home and abroad. For the future development trend of LNG vehicle and technical route, the following are described:

1) Because the size of the electronic regulator and mixer is larger and the arrangement is difficult, in order to obtain more ideal combustible mixture, it is necessary to study the improvement of the mixer.

2) Optimization of LNG low temperature storage time. When the vehicle is standing for a long time, LNG will be vaporized which leads to the pressure inside the cylinder increased. In order to increase the time of storaging, a small liquefaction device can be arranged in the cylinder and used for liquefied gas, which can ensure the safety and increase the storage time.

3) Cold energy of LNG has been reflected in the supply system. In addition, cold energy can also be used in the air conditioning system of the vehicle and it can play the effect of energy conservation.

4) In the gas supply system, direct injection can be used. In the future development of LNG vehicles, the way of LNG liquid direct injection can be considered, which can greatly improve the efficiency of charging.

\section{REFERENCES}

[1] D. Wen and J. Lu, "Overall statement on liquefied natural gas (LNG) vehicle,” Equipment Manufacturing Technology, vol. 7, pp. 120-123, 2012.

[2] Y. Wen and Y. Chen, "Development of LNG vehicles technology and its prospect of popularization and application," Chemical Engineering of Oil and Gas, vol. 42, pp. 257-260, 2013.

[3] Y. Liang, “Analysis of LNG vehicle cylinder and air supply system,” A Study on National Business Situation and Theory, vol. 38, pp. 64-65, 2013.

[4] B. Wu and S. Chen, "Process and equipment for LNG supply system for vehicles,” Gas \& Heat, vol. 32, pp. 9-12, 2012.

[5] L. He and Z. Zhao, "Analysis of technology and equipment for liquefied natural gas supply system,” Chemical Industry Management, vol. 33, pp. 96-97, 2014.

[6] L. Jiang, "Research on installation technology of bus LNG supply system,” Bus \& Coach Technology and Research, vol. 5, pp. 26-28, 2011.

[7] L. Wei, "Development and application of gas supply system for LNG vehicle,” Design Research, vol. 6, pp. 27-30, 2012.

[8] S. Jin and S. Chen, "Analysis of the stable gas supply and gasification quantity of self-pressurization for LNG vehicle cylinder," Refrigeration, vol. 41, pp. 59-62, 2013.

[9] M. Du, "Design and analysis of LNG vehicle cylinder," thesis, Hefei University of Technology, China, 2016.
[10] H. Yuan, "Research on the carburetor of the LNG engine," thesis, Taiyuan University of Technology, Taiyuan, China, 2015.

[11] R. Wu and J. Xia, “Analysis on vaporization volume of water-bath type vaporizer in LNG vehicle,” Automobile Applied Technology, vol. 5, pp. 75-77, 2016.

[12] B. Hu, "The study and design of the vaporizer heated by exhaust for the gas supply system of LNG vehicle,” thesis, Shanghai University of Engineering Science, Shanghai, China, 2014.

[13] P. Wang, "Research on fuel gasification control of LNG power ship," thesis, Maritime Affairs University of Dalian, Dalian, China, 2013.

[14] X. Su, L. Zhang, and J. Chen, "Present situation of research and application of CNGV and LNGV in China,” Natural Gas and Oil, vol. 25, pp. 8-12, 2007.

[15] M. Jian, "Study on flow characteristics of mixer for gas vehicle," thesis, Sichuan Institute of Technology, China, 2001.

[16] D. Zhao, “Optimization design of the mixer,” Automotive Engineering, vol. 7, pp. 11-14, 2003.

[17] J. Yu, "The principle of CNG / LNG heavy truck air supply system, composition and case analysis,” Vehicle Repair and Maintenance, vol. 1, pp. 77-79, 2014

[18] R. Lian, H. Wang, and X. Jiang, "Research on development of vehicular LNG-fuel supply system,” Automobile Applied Technology, vol. 8, pp. 4-6 2016

[19] A. A. F. Al-Kubati, "Research on application technology of natural gas vehicle,” Ph.D. dissertation, Chang'an University, Xi’an, China, 2014.

[20] P. Meyers, G. D. Bourn, and J. C. Hedrick, "Evaluation of six natural gas combustion systems for LNG locomotive applications,” in Proc. of International Fuels \& Lubricants Meeting \& Exposition, 1997.

[21] J. Wang, Z. Huang, and Y. Fang, "Combustion behaviors of a direct-injection engine operating on various fractions of natural gas hydrogen blends," International Journal of Hydrogen Energy, vol. 32, pp. 3555-3564, 2007.

[22] B. Alberto and C. W. Harry, "The lean burn direct injection jet ignition gas engine,” International Journal of Hydrogen Energy, vol. 34, pp. 7835-7841, 2009.

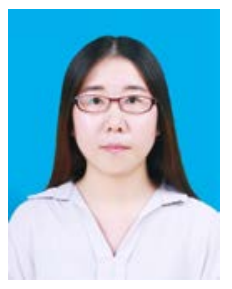

Ping Fang is a Postgraduate of College of Mechanical Engineering, Shanghai University of Engineering Science. She was born in Jiangsu province of China and she lives in Shanghai now. Her current research is liquefied natural gas vehicle. She studied at Changzhou Institute of Engineering and won many scholarships as a graduate student and a third prize in mathematical modeling for Chinese graduate students.

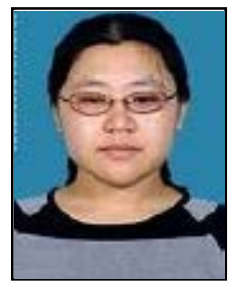

Yu Chen graduated from Shanghai Jiao Tong University in December 2007, majored in refrigeration and cryogenic engineering and received his doctorate. In the same year, she entered the department of thermal energy and power engineering of the Institute of Mechanical Engineering of Shanghai University of engineering and technology as a full-time teacher, and was recruited as an associate professor in 2009. At present, she is mainly engaged in the physical properties of cryogenic fluids and is stored in transportation and other fields. During her tenure, she obtained the Shanghai natural science foundation project and two national natural science fund cooperation projects. 